\title{
The Impact of Dopamine on Insulin Secretion in Healthy Controls
}

\author{
Lisa J. Underland, Erika R. Mark, Ranjitha Katikaneni, Rubina Heptulla \\ Department of Pediatrics, Division of Endocrinology and Diabetes, Children's Hospital at Montefiore, Bronx, New York, USA
}

\section{Abstract}

Objective: Dopamine is very commonly used in the critical care setting and impacts glucose homeostasis. In some studies, it is noted to increase insulin resistance or decrease insulin secretion. The role of insulin secretion in response to dopamine is incompletely understood. Methods: Eight individuals underwent a hyperglycemic clamp with a dopamine infusion, and eight controls underwent hyperglycemic clamp alone. Insulin, C-peptide, glucagon, cortisol, and norepinephrine (NE) concentrations were measured at various time points. An index of insulin sensitivity (M/I) was calculated. Statistical comparison between the control and treatment arm was done using repeated measures ANOVA. The data is expressed as mean \pm standard deviation. Paired $t$-test was used to compare pre- and post-dopamine infusion time points in the study individuals only. Data was considered to be statistically significant at $P<0.05$. Results: On assessing the treatment group before and during dopamine infusion, insulin and C-peptide concentrations were higher at the time of the infusion $(P=0.02$ and $P=0.003$, respectively). The index of insulin sensitivity was not statistically different. There was a significant decrease in insulin $(P=0.002), \mathrm{C}$-peptide $(P=0.005)$, and NE $(P<0.0001)$ concentrations in the treatment group, compared to the controls. Glucagon concentration was higher in the treatment group $(P=0.02)$. Conclusion: In this study, dopamine infusion did not adversely impact insulin secretion.

Keywords: Dopamine, glucose, hyperglycemia, insulin sensitivity, pressors

\section{INTRODUCTION}

Dopamine is a commonly used medication in critical care medicine. The focus of this study is on the impact of dopamine (a commonly used medicine in critically ill patients) on endogenous insulin release. In vitro and in vivo studies have shown that dopamine receptors have a role in insulin secretion.

In vitro studies suggest that dopamine inhibits glucose-stimulated insulin secretion in the pancreas. ${ }^{[1]}$ It has been posited that this may be due to downregulation of D2-like receptors causing increased release of catecholamines, decreased cell membrane depolarization, and cytosolic calcium influx causing a decrease in insulin secretion. ${ }^{[2]}$

In mice, dopamine administration resulted in the loss of glucose-stimulated insulin secretion. ${ }^{[3]}$ This was not shown in D2 receptor knockout mice; therefore, illustrating that disruption in D2 receptors leads to impaired insulin secretion from the pancreas and causes glucose intolerance. ${ }^{[3]}$ In humans, circulating dopamine levels are inversely proportional to

\begin{tabular}{|l|l|}
\hline \multicolumn{3}{|c|}{ Access this article online } \\
\hline Quick Response Code: & Website: \\
& www.ijccm.org \\
& \\
&
\end{tabular}

C-peptide levels, reflecting decreased prehepatic secretion of insulin when dopamine levels are high. ${ }^{[4]}$

Dopamine is a natural catecholamine and a neurotransmitter in the central nervous system and a precursor to both epinephrine and norepinephrine (NE). It exerts its action through alpha, beta, and dopaminergic receptors. Intermediate dosing (5-10 $\mathrm{mcg} / \mathrm{kg} / \mathrm{min})$ mostly results in chronotropic and inotropic effects through beta-receptor agonism such as an increase in heart rate and systolic blood pressure. As the dopamine dose is increased, it interacts with alpha-receptors, causing an increase in systemic vascular resistance. ${ }^{[5]}$

Although many animal studies and in-vitro studies suggested that a relationship may exist between dopamine and insulin

Address for correspondence: Dr. Lisa J. Underland Department of Pediatrics, Division of Endocrinology and Diabetes, Children's Hospital at Montefiore, 3411 Wayne Ave, $4^{\text {th }}$ Floor Suite 4M, Bronx, New York 10467, USA. E-mail: lunderla@montefiore.org

This is an open access journal, and articles are distributed under the terms of the Creative Commons Attribution-NonCommercial-ShareAlike 4.0 License, which allows others to remix, tweak, and build upon the work non-commercially, as long as appropriate credit is given and the new creations are licensed under the identical terms.

For reprints contact: reprints@medknow.com

How to cite this article: Underland LJ, Mark ER, Katikaneni R, Heptulla R. The impact of dopamine on insulin secretion in healthy controls. Indian J Crit Care Med 2018;22:209-13. 
secretion, the role of dopamine on beta cells in humans is less understood. This is important to assess because if healthy subjects/individuals have a reduction in insulin secretion during dopamine infusion following hyperglycemic clamp, it would suggest that this would likely be exacerbated during stress and circulatory collapse in the intensive care unit. Ultimately, this could lead to hyperglycemia which could impact patient outcomes and mortality.

Studies in humans are lacking on the impact of dopamine in the clinically stable and the critically ill setting. We therefore investigated the role of dopamine infusion using a hyperglycemic clamp and its effects on insulin secretion first in clinically stable individuals.

\section{Methods}

This study was an open-label, prospective, and single-center interventional trial. Institutional Review Board approval was obtained. Investigations were carried out according to the Declaration of Helsinki. The trial is listed on ClinicalTrials. gov, NCT02053935.

\section{Study subjects}

A total of fourteen individuals were recruited for the study. Twelve individuals underwent either a control visit or a study visit and two individuals underwent both the control and study visit. Individuals were recruited from the clinics and through online postings on clinical trial sites. All were healthy adults between 18-35 years of age without anemia, hypertension, diabetes, or signs of polycystic ovarian syndrome (PCOS). They were found to have normal thyroid function, cholesterol, kidney function, electrocardiography (EKG), and liver function tests. Body mass index (BMI) was between $18.5-25 \mathrm{~kg} / \mathrm{m}^{2}$ and Hemoglobin A1c was $<6 \%$.

\section{Study procedures}

After obtaining written informed consent, individuals underwent screening at the clinical research center (CRC). Individuals came in after an overnight fast. At this visit, a complete history and physical examination including vital signs, height, weight, BMI, waist circumference, and an EKG were obtained. Baseline labs were drawn for complete blood count, chemistry, liver function tests, hemoglobin A1C, thyroid function tests, lipids, and cortisol. Female individuals had a urine beta-HCG test, to rule out pregnancy.

Individuals that met the study criteria returned to the CRC, after an overnight fast. All individuals were asked to consume a weight-maintaining diet for 3 days before the study visit. Vitals as well as baseline labs were obtained, and two intravenous lines were placed, one for blood sampling and one for a solution of $20 \%$ dextrose. Hyperglycemic clamp was performed as previously described, with target hyperglycemia $125 \mathrm{mg} / \mathrm{dL}$ above baseline. ${ }^{[6]}$ The individuals received a 15 -min priming dextrose dose, and then, dextrose solution was titrated to raise blood sugars to a hyperglycemic level. During the first hour of the study, both groups received glucose only to achieve stabilization of blood sugars in a hyperglycemic range. For those on the study, dopamine was started at $60 \mathrm{~min}$ and then titrated up to $5 \mathrm{mcg} / \mathrm{kg} / \mathrm{min}$ until $240 \mathrm{~min}$. Blood pressure was measured every $10 \mathrm{~min}$ during dopamine infusion, and systolic blood pressure was maintained at $<160 \mathrm{mmHg}$. During the control visit, vital signs were measured every $20 \mathrm{~min}$.

Blood glucose (BG) concentrations were measured at bedside using an Analox GM9 analyzer ${ }^{\circledR}$ (Analox instruments, UK) every $10 \mathrm{~min}$, starting from $0 \mathrm{~min}$ to $240 \mathrm{~min}$; blood was drawn every 30 min to measure insulin, C-peptide, glucagon, cortisol, and catecholamine concentrations (epinephrine and NE), starting at $60 \mathrm{~min}$ until the end of the study (240 min). Infusions were stopped at $240 \mathrm{~min}$, and glucose was gradually weaned off. Individuals were given lunch and were euglycemic before discharge.

\section{Hormone analysis}

Glucagon and insulin assays were performed in the core laboratories of Einstein Institute for Clinical and Translational Research, ${ }^{[7]}$ using a Mercodia enzyme-linked immunosorbent assay (ELISA) kit (Cat. No: 10-1271-01, Winston Salem, NC) and an EMD Millipore radioimmunoassay (RIA) kit (HI-14K, Billerica, MA). The lower limit of quantification for glucagon is $25 \mathrm{pg} / \mathrm{ml}$, with an intra-assay coefficient of variation (CV) ranging from $5.1 \%$ to $3.3 \%$ and an inter-assay $\mathrm{CV}$ ranging from $8.1 \%$ to $7.3 \%$. The detection limit for insulin is $3 \mathrm{uU} / \mathrm{mL}$, with an inter-assay $\mathrm{CV}$ ranging from $2.9 \%$ to $6.0 \%$ and an intra-assay $\mathrm{CV}$ ranging from $2.2 \%$ to $4.4 \%$. The cortisol assay was run using an ELISA kit (ALPCO, Cat. No: 11-CORHU-E01, Salem, NH). The sensitivity of this assay is $0.4 \mu \mathrm{g} / \mathrm{dl}$, with an intra-assay $\mathrm{CV}$ ranging from $9.4 \%$ to $5.0 \%$ and an inter-assay $\mathrm{CV}$ ranging from $8.1 \%$ to $3.8 \%$. Assay for C-Peptide was run, using a radioimmunoassay kit (RIA) from EMD Millipore (HCP-20K, Billerica, MA); with a sensitivity of $0.1 \mathrm{ng} / \mathrm{ml}$. Catecholamines were analyzed using a high-performance liquid chromatography with electrochemical detection.

\section{Calculations and statistical analysis}

During the hyperglycemic clamp procedure, M (rate of glucose metabolism) was calculated with the following equation: $\mathrm{M}=\mathrm{INF}-\mathrm{SC}$. INF is glucose infusion rate and SC represents correction for the glucose space changes. The index of insulin sensitivity $(\mathrm{M} / \mathrm{I})$, representing the rate of glucose metabolism over insulin level, was calculated for both control and treatment groups at $210 \mathrm{~min}$ and $240 \mathrm{~min}$. Further, the study individuals also had the index of insulin sensitivity (M/I) calculated at $30 \mathrm{~min}$ (before dopamine infusion) and at $210 \mathrm{~min}$ (during dopamine infusion).

Statistical analysis was performed using GraphPad Prism 6.0 (GraphPad Software Inc., San Diego, CA). Comparisons were done using repeated measures ANOVA between the controls and treated individuals, and a paired $t$-test was used to compare pre- and post-dopamine infusion time points in the study individuals only. All values are represented as mean \pm standard deviation, unless otherwise specified. The data for variability 
between the groups as well as the pre- and post-dopamine infusion time points are expressed as mean $+/-95 \%$ confidence interval (CI). Differences were considered to be statistically significant at $P<0.05$.

\section{RESULTS}

Table 1 depicts patient demographics. Overall, twenty-eight participants were screened and fourteen individuals qualified and completed the study visits ( 2 individuals completed both control and treatment visits on separate occasions). Screen fails were due to: high BMI $(n=2)$, elevated creatinine level $(n=1)$, difficulty in contacting individual after screen $(n=1)$, hypertension $(n=1)$, anemia $(n=3)$, and elevated liver function tests $(n=1)$, and hyperglycemia on the day of the study visit $(n=1)$. Complications were noted for one individual in the study group with extravasation during the dopamine infusion (the intravenous line infiltrated with $10 \mathrm{~mL}$ of dopamine and dextrose 20\% [D20]). Individual was given phentolamine, and warm pack was applied with resolution of symptoms. They were not able to complete the study and were not included in the analysis. In the control group, 3 patients were unable to complete the study visit due to IV issues (the intravenous lines required replacement due to the use of D20 and the individuals were not able to tolerate this).

\section{Control versus treatment}

Average BG levels during the studies were $200 \mathrm{mg} / \mathrm{dl}$ for the study arm and $200.5 \mathrm{mg} / \mathrm{dl}$ for the control arm.

Insulin concentrations were significantly lower in the treatment group, compared to the controls $(86.0 \pm 21.5$ vs.

\begin{tabular}{|c|c|c|}
\hline & Control & Treatment \\
\hline Males (No.) & $100 \%$ (8 males) & $\begin{array}{c}87.5 \% \\
(7 \text { males, } 1 \text { female) }\end{array}$ \\
\hline Age (years) & $28.0 \pm 2.8$ & $27.6 \pm 2.6$ \\
\hline \multicolumn{3}{|l|}{ Race (\%) } \\
\hline Caucasian & 25 & 50 \\
\hline African American & 50 & 37.5 \\
\hline Asian & 25 & 0 \\
\hline Hispanic & 0 & 12.5 \\
\hline Weight (kg) & $73.3 \pm 6.8$ & $75.3 \pm 7.4$ \\
\hline Height (cm) & $179.0 \pm 5.0$ & $177.0 \pm 5.9$ \\
\hline BP systolic (mmHg) & $122.0 \pm 9.2$ & $126.6 \pm 6.2$ \\
\hline BP diastolic (mmHg) & $73.1 \pm 8.3$ & $71.1 \pm 5.1$ \\
\hline BMI $\left(\mathrm{kg} / \mathrm{m}^{2}\right)$ & $22.8 \pm 2.1$ & $24.0 \pm 1.2$ \\
\hline Hemoglobin A1c (\%) & $5.4 \pm 0.34$ & $5.3 \pm 0.32$ \\
\hline Cortisol (ug/dl) & $16.1 \pm 6.2$ & $10.3 \pm 3.4$ \\
\hline Total cholesterol (mg/dl) & $151.6 \pm 35.3$ & $176.0 \pm 28.3$ \\
\hline Triglycerides (mg/dl) & $63.0 \pm 31.6$ & $73.5 \pm 48.1$ \\
\hline AST (U/L) & $22.9 \pm 6.3$ & $22.9 \pm 6.3$ \\
\hline $\operatorname{ALT}(\mathrm{U} / \mathrm{L})$ & $17.8 \pm 4.0$ & $27.4 \pm 17.8$ \\
\hline
\end{tabular}

All data are expressed as mean $\pm \mathrm{SD}$, except for sex and race.

SD: Standard deviation; BP: Blood pressure; BMI: Body mass index; AST: Aspartate aminotransferase; ALT: Alanine aminotransferase
$127.4 \pm 33.0 \mu \mathrm{U} / \mathrm{ml}, P=0.002)$; the mean difference being -41.5 $\mu \mathrm{U} / \mathrm{ml}(95 \%$ CI: $-60.9,-22.1)$ [Figure 1a]. Similarly, C-peptide concentrations were also lower in the treatment group ( $6.81 \pm 0.8$ vs. $8.96 \pm 2.0 \mathrm{ng} / \mathrm{ml}, P=0.005)$, compared to the controls; the mean difference between the groups is $-2.15 \mathrm{ng} /$ $\mathrm{ml}(95 \% \mathrm{CI}:-3.36,-0.95)$ [Figure 1b]. However, serum glucagon concentrations were significantly higher in the treatment group, compared to controls $(1.74 \pm 0.6$ vs. $1.15 \pm 0.4 \mathrm{pmol} / \mathrm{L}, P=0.02)$. There was a significant mean difference between the treatment and control groups, $0.60 \mathrm{pmol} / \mathrm{L}(95 \% \mathrm{CI} 0.15,1.03)$ [Figure 1c]. Cortisol concentrations were not statistically significant between the treatment and control groups ( $16.7 \pm 3.0 \mathrm{vs.} 15.8 \pm 1.5 \mu \mathrm{g} / \mathrm{dl}$, $P=0.43)$. NE concentrations were significantly lower in those receiving dopamine compared to the controls $(285.6 \pm 33$ vs. $375.0 \pm 25 \mathrm{pg} / \mathrm{ml}, P<0.0001$ ), and there was a significant mean difference in NE concentrations between the treatment and control groups $-89.4 \mathrm{pg} / \mathrm{ml}$ (95\% CI: $-104.5,-74.3)$. Figure 2 indicates that the $(\mathrm{M} / \mathrm{I})$ index of insulin sensitivity was not different between the control and treatment groups, at 210 and $240 \mathrm{~min}$ time points $(0.21 \pm 0.01$ vs. $0.16 \pm 0.02$, $P=0.17$ ) [Figure 2].

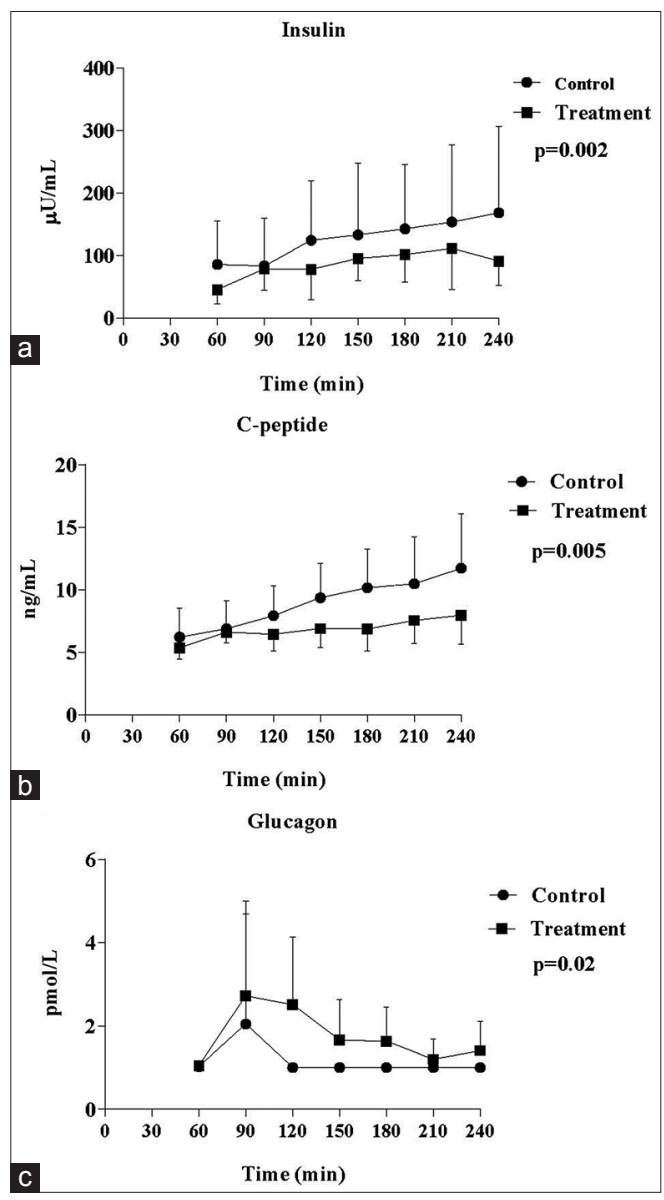

Figure 1: Insulin, C-peptide, and glucagon concentrations (a-c) were analyzed during the time points, 60-240 min and are represented as black circles - control and black squares - treatment. All data are expressed as mean \pm standard deviation. $P<0.05$ was considered to be statistically significant. Difference between the groups is expressed as mean $+/-95 \%$ confidence interval 


\section{Treatment group only}

Insulin sensitivity was compared at two time points, $30 \mathrm{~min}$ (during the hyperglycemic clamp but before dopamine infusion) and at $210 \mathrm{~min}$ (during the hyperglycemic clamp following dopamine infusion). This was done to compare insulin sensitivity before infusion to insulin sensitivity following dopamine infusion. Insulin concentrations were significantly different between 30 and $210 \mathrm{~min}$ time points, with treatment levels being higher at the $210 \mathrm{~min}$ time point $(35.1 \pm 6.1$ vs. $111.3 \pm 23.4 \mu \mathrm{U} / \mathrm{ml}$, $P=0.02)$, the difference being $-76.3 \mu \mathrm{U} / \mathrm{ml}(95 \% \mathrm{CI}$ : -138.1, -14.5) [Figure 3a] C-peptide concentrations were also significantly higher in the treatment group at 210 min time point, which corresponds to dopamine infusion $(4.19 \pm 0.3$ vs. $7.54 \pm 0.7 \mathrm{ng} / \mathrm{ml}, P=0.003)$. The mean difference between the two time points is $-3.34 \mathrm{ng} / \mathrm{ml}(95 \% \mathrm{CI}: 5.13,-1.56)$ [Figure 3b]. The index of insulin sensitivity $(\mathrm{M} / \mathrm{I})$ was not statistically significant between the two time points $(30 \mathrm{~min}$, prior to dopamine infusion and at $210 \mathrm{~min}$, following dopamine infusion) $(0.43 \pm 0.2$ vs. $0.18 \pm 0.04, P=0.18)$, with a mean difference of 0.25 (95\% CI: $-0.14,0.65)$ [Figure $3 \mathrm{c}$ ].

\section{Discussion}

Our study found that when comparing the individual's pre- and post-dopamine infusion in the setting of a hyperglycemic clamp, insulin and C-peptide concentrations were higher with dopamine. We therefore decided to compare these results to a control group which underwent the hyperglycemic clamp without dopamine. When comparing treatment and controls, C-peptide and insulin concentrations were lower for the treatment group (dopamine) compared to the controls (no dopamine). However, the index of insulin sensitivity was not statistically different suggesting that dopamine does not affect insulin sensitivity acutely. Glucagon concentrations were higher in the individuals who received dopamine, compared to controls.

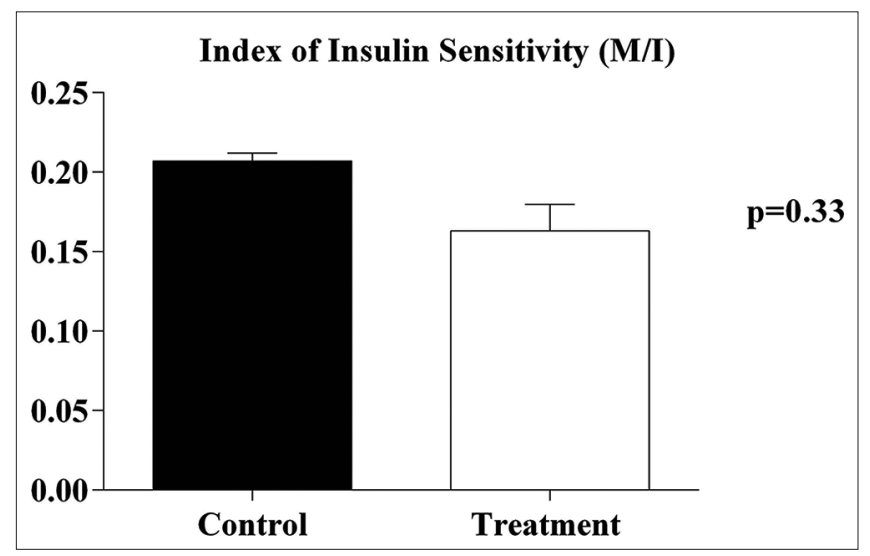

Figure 2: Index of insulin sensitivity (M/l) was calculated at time points, $210 \mathrm{~min}$ and $240 \mathrm{~min}$ and is represented as black bars for control and white bars for treatment. The data are expressed as mean \pm standard deviation. $P<0.05$ was considered to be statistically significant
Assessment of the relationship of insulin and dopamine is fraught with contradiction, as one must consider both central and peripheral actions. Centrally, it has been shown that insulin increases dopamine release which can impact food choices. ${ }^{[8]}$

Peripherally, Tomaschitz et al. evaluated fasting dopamine and C-peptide levels in patients with hypertension but without diabetes and found an inverse association between C-peptide and dopamine levels. ${ }^{[4]}$ Bahler evaluated individuals taking dopamine agonists with fasting oral glucose tolerance and demonstrated an increase in sensitivity and insulin area under the curve in both lean and obese individuals. ${ }^{[9]}$

Previous studies have shown that for healthy controls, insulin concentrations increased with the use of dopamine ${ }^{[5]}$ This was assessed by Ruttimann et al. ${ }^{[10]}$ by providing IV dopamine at different rates in healthy adults, and it was found that the dopamine increased glucose levels and also plasma insulin levels. In addition, Contreras et al. infused dopamine in adults with and without diabetes and noted an increase in insulin with dopamine infusion. This study had individuals receiving initially a $90 \mathrm{~min}$ placebo, then dopamine antagonist for $30 \mathrm{~min}$, and then metoclopramide plus dopamine for $30 \mathrm{~min}$ and

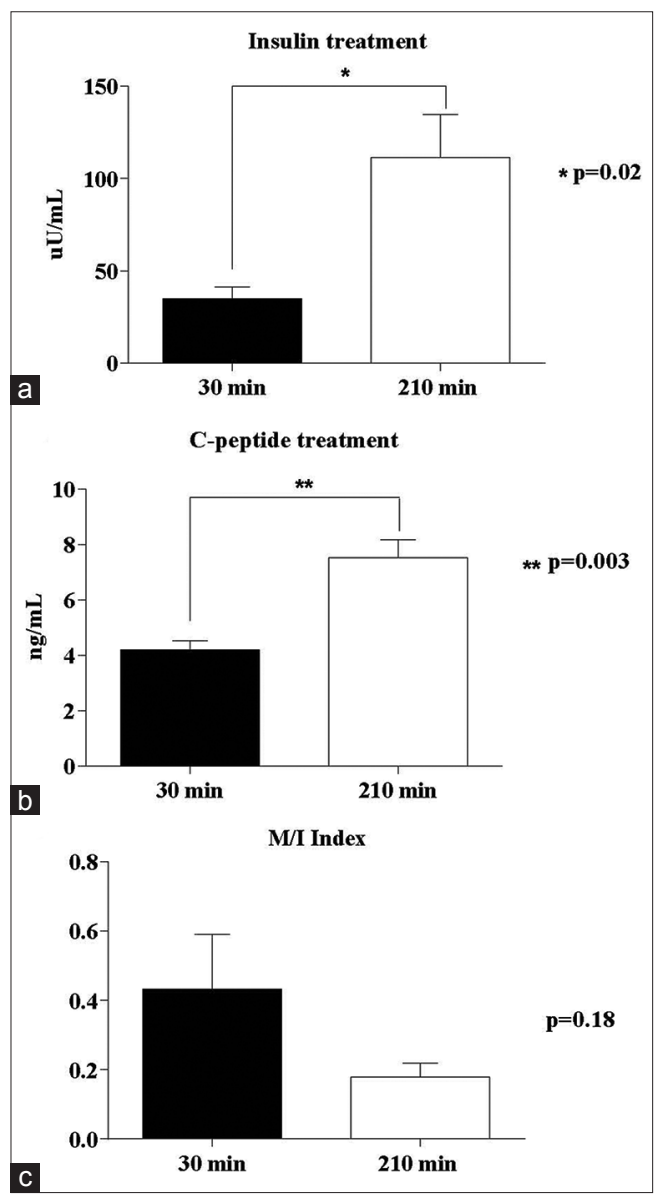

Figure 3: Insulin concentrations (a), C-peptide (b), and index of insulin sensitivity - $M / I$ (c). Data are expressed as mean \pm standard deviation and statistically significant at $P<0.05$. The variability between the time points is expressed as mean $\pm 95 \%$ confidence interval 
comparing various parameters between the groups. ${ }^{[5]}$ However, our study found that insulin levels were lower with dopamine infusion, which seems in contradiction to these previous results.

Glucagon concentrations were more suppressed in the control group rather than the treatment individuals. In addition, there was no difference in glucagon concentrations; when individuals at $30 \mathrm{~min}$ time point before dopamine infusion were compared to individuals at $210 \mathrm{~min}$ during dopamine infusion. It should be noted that the dopamine studies (individuals treated with dopamine) were done first, and it is possible with time that the samples became less accurate to assess glucagon concentrations. ${ }^{[11]}$ Ultimately, most of the glucagon concentrations were suppressed likely reflecting the higher insulin concentrations noted in both groups rather than an effect of the dopamine.

The two limitations of our study are the following (1) small sample size and (2) the study was designed to compare insulin release with and without dopamine. Data would perhaps have been more meaningful if we had been able to compare the same individuals on different days with and without the dopamine. Further, differences between the study individuals with regard to innate insulin sensitivity could have impacted the results. Comparing the same individuals, pre-dopamine infusion and during dopamine infusion in the treatment group does somewhat mitigate these differences; but then, it does not account for changes in insulin secretion over time in the setting of a hyperglycemic clamp.

\section{Conclusion}

Dopamine infusion did not adversely impact insulin secretion or sensitivity. Further studies in larger cohorts are needed to elucidate the relationship between dopamine infusion and insulin secretion. This is an important consideration in patients in the intensive care unit receiving dopamine infusions although in these settings, the confounding factor of critical illness is unclear.

\section{Acknowledgment}

We would like to thank all research participants for their participation in the study. We would also like to acknowledge the staff at the clinical research center at Montefiore for their assistance in this project.

Financial support and sponsorship

Nil.

\section{Conflicts of interest}

There are no conflicts of interest.

\section{RefEREnCES}

1. Shankar E, Santhosh KT, Paulose CS. Dopaminergic regulation of glucose-induced insulin secretion through dopamine D2 receptors in the pancreatic islets in vitro. IUBMB Life 2006;58:157-63.

2. Rubí B, Ljubicic S, Pournourmohammadi S, Carobbio S, Armanet M, Bartley C, et al. Dopamine D2-like receptors are expressed in pancreatic beta cells and mediate inhibition of insulin secretion. J Biol Chem 2005;280:36824-32.

3. García-Tornadú I, Ornstein AM, Chamson-Reig A, Wheeler MB, Hill DJ, Arany E, et al. Disruption of the dopamine d2 receptor impairs insulin secretion and causes glucose intolerance. Endocrinology 2010;151:1441-50.

4. Tomaschitz A, Ritz E, Kienreich K, Pieske B, März W, Boehm BO, et al. Circulating dopamine and $\mathrm{C}$-peptide levels in fasting nondiabetic hypertensive patients: The Graz Endocrine Causes of Hypertension Study. Diabetes Care 2012;35:1771-3.

5. Contreras F, Foullioux C, Pacheco B, Maroun C, Bolívar H, Lares M, et al. Effect of drugs interacting with the dopaminergic receptors on glucose levels and insulin release in healthy and type 2 diabetic subjects. Am J Ther 2008;15:397-402.

6. DeFronzo RA, Tobin JD, Andres R. Glucose clamp technique: A method for quantifying insulin secretion and resistance. Am J Physiol 1979;237:E214-23.

7. Crandall JP, Oram V, Trandafirescu G, Reid M, Kishore P, Hawkins M, et al. Pilot study of resveratrol in older adults with impaired glucose tolerance. J Gerontol A Biol Sci Med Sci 2012;67:1307-12.

8. Stouffer MA, Woods CA, Patel JC, Lee CR, Witkovsky P, Bao L, et al. Insulin enhances striatal dopamine release by activating cholinergic interneurons and thereby signals reward. Nat Commun 2015;6:8543.

9. Bahler L, Verberne HJ, Brakema E, Tepaske R, Booij J, Hoekstra JB, et al. Bromocriptine and insulin sensitivity in lean and obese subjects. Endocr Connect 2016;5:44-52.

10. Ruttimann Y, Schutz Y, Jéquier E, Lemarchand T, Chioléro R. Thermogenic and metabolic effects of dopamine in healthy men. Crit Care Med 1991;19:1030-6.

11. Wewer Albrechtsen NJ, Veedfald S, Plamboeck A, Deacon CF, Hartmann B, Knop FK, et al. Inability of some commercial assays to measure suppression of glucagon secretion. J Diabetes Res 2016;2016:8352957. 